\title{
BMJ Open Effects of health status on work exit and absenteeism among the older working population in China: a secondary analysis of a cohort sample
}

Xin Li, ${ }^{1}$ Wei Zhang, ${ }^{\circledR 2,3}$ Huiying Sun, ${ }^{2}$ Aslam H Anis ${ }^{2,3}$

To cite: Li X, Zhang W, Sun $\mathrm{H}$, et al. Effects of health status on work exit and absenteeism among the older working population in China: a secondary analysis of a cohort sample. BMJ Open 2019;9:e024115. doi:10.1136/ bmjopen-2018-024115

- Prepublication history and additional material for this paper are available online. To view these files, please visit the journal online (http://dx.doi org/10.1136/bmjopen-2018024115).

$\mathrm{XL}$ and $\mathrm{WZ}$ contributed equally.

Received 10 May 2018

Revised 10 July 2019

Accepted 20 August 2019

A Check for updates

C Author(s) (or their employer(s)) 2019. Re-use permitted under CC BY-NC. No commercial re-use. See rights and permissions. Published by BMJ.

${ }^{1}$ School of Social and Public Administration, East China University of Science and Technology, Shanghai, China ${ }^{2}$ Centre for Health Evaluation and Outcome Sciences, Vancouver, British Columbia, Canada

${ }^{3}$ School of Population and Public Health, University of British Columbia, Vancouver, British Columbia, Canada

Correspondence to Dr Xin Li; xinli@ecust.edu.cn

\section{ABSTRACT}

Objectives To analyse the effects of health status on work exit and absenteeism among the older working population in China.

Design Secondary analysis of a cohort sample. Setting and participants Community samples who engaged in either agricultural or non-agriculture work or both in the 2011 wave of the China Health and Retirement Longitudinal Study (CHARLS) and whose age was 45-55 years for women or 45-60 years for men in the 2013 wave.

Outcome measures Work exit and number of absent workdays due to health problems in 2013. To address the problems of measurement error of self-rated health status, we used disability condition, number of chronic diseases and functional limitation to construct an index of health. We divided the sample into four groups according to gender and work types (farmers who conducted any agricultural work in 2011 vs non-farmers who conducted non-agricultural work only) and conducted analyses separately.

Results Farmers ( $11.0 \%$ for women and $4.9 \%$ for men) were less likely to exit from work than non-farmers (18.5\% and $12.0 \%$, respectively) but took more absent workdays ( 16.6 days for women and 15.0 days for men) than non-farmers (5.6 and 4.9). Poor health status in 2011 was significantly associated with the work exit in 2013 of female and male farmers but not non-farmers. Older workers (except female non-farmers) with persistently poor health or recent health deterioration over time were significantly more likely to stop working or missed more workdays than those with persistently good health.

Conclusions Poor 2-year lagged health predicts work exit for both male and female farmers, and increases the absent work days in all older working population. Persistently poor health or recent health deterioration over time has detrimental impact on labour market in terms of work exit and absenteeism among all older Chinese workers except for female non-farmers.

\section{INTRODUCTION}

China has become one of the fastest ageing countries in the world. ${ }^{1}$ The number of people in labour force (aged 18-64 years) is expected to decline by approximately 140 million in 2050 even under the current

\section{Strengths and limitations of this study}

- We analysed the effects of the lagged health status and the evolution of health status over time on work exit and absenteeism among the older working population in China.

- We measured two outcomes: work exit and the number of absent workdays due to health problems among those who remained working.

- To address the problems of measurement error of self-rated health status, we used three detailed health measures to construct an index of health in our analyses.

- We only selected working population in 2011 which might underestimate the effect of health status.

universal two-child policy. ${ }^{2}$ The rapid growth of the older population and shrinking labour force raise many problems in Chinese society. One of the prominent problems is a possible threat to the stability and sustainability of the current social pension system of China. The shrinking labour force will contribute less to the retirement income system and an increasing aged population will be eligible to receive retirement pensions. Therefore, the combination of the two trends could significantly impact economic growth adversely and cause the pension fund to become bankrupt.

Currently, China's labour market has shown the following two characteristics. On one hand, the employment rate among older population in the urban area (mainly conducting non-agricultural work) is very low, it only reaches $40 \%$ among people between 50 and 59 , and this rate decreases further to about $20 \%$ for those aged $60-64 .^{3}$ This might be due to the official mandatory retirement policies implemented in the urban formal sectors. ${ }^{4}$ Specifically, the retirement age for men is 60 years and for women, it is 55 for civil servants and employees for state enterprises, and 50 for others. On the other hand, 
the employment rate among older population in the rural area (mainly conducting agricultural work) is very high, most people still work between 65 and 69 , and by the age of 80 , the employment rate is still above $20 \%{ }^{3}$ This divergence of employment for the urban and rural areas is mainly due to the fact that the retirement policy, the pension programme and unemployment insurance programme are limited only to the urban formal sectors in China but not to the rural population. Considering that the older population has become or will become the main component of labour force in China, it is crucial to keep them active and productive in the labour market to maintain sufficient labour supply and contain the increasing national spending on income support.

Labour market status are affected by many factors, among which the influence of health on labour supply has attracted more and more attention. Specifically, people would have to stop working due to their poor health status or frequently take sick leaves while remaining working. It is important and necessary to study the effect of health status on work exit and absenteeism among the older working people for the following two reasons. First, it helps policy-makers better understand the impact of health on labour market activities and therefore they will be able to develop appropriate policies to encourage older working people to not only remain active in the labour market but also remain productive. Second, it helps policy-makers better understand the consequence of poor health, which includes not only the higher healthcare expenditures but also the productivity losses attributable to work exit and absenteeism.

There is a vast literature that demonstrates poor health has a significant impact on work exit in the developed countries especially among older population. In these economic and epidemiological studies, poor health has been measured by self-rated health $(\mathrm{SRH}),{ }^{5-13}$ chronic diseases such as depression, ${ }^{14}$ rheumatoid arthritis, ${ }^{15}$ diabetes ${ }^{16}$ cancer $^{17}$ and functional limitations. ${ }^{18}$ Many studies have also shown the impact of one specific disease on the number of absent workdays among people with the disease. ${ }^{19-25}$ However, worldwide, there are only a few studies from the developed countries that measure the number of absent workdays in the general population due to a lack of data. ${ }^{26-30}$ Most studies to date have focused on either comparing the incremental effects of different chronic diseases on absent workdays or estimating the incremental productivity loss due to different chronic diseases. $^{26-31}$ Overall, there are few studies analysing the effect of health on work exit or absenteeism in the developing countries, ${ }^{32}$ especially among older working population.

In addition, most of the previous studies have examined the static relationship between health and work exit. However, the relationship can be a dynamic process. Studies have shown that not only the current health status but also the previous health status affect decisions concerning work exit. ${ }^{9}{ }^{10}$ Therefore, the impact of persistently poor health might be different from that of recent health deterioration. To fill the literature gap, this present paper was to examine the effects of health status on work exit and absenteeism among the older working population in China. Specifically, we measured the impact of previous health status and the change of health status over time on work exit and the number of absent workdays due to the health problems among the older people who were previously working. Our hypotheses were: (1) those with poorer previous health status were expected to be more likely to exit from work or missed more workdays; (2) those with persistently poor health were expected to be most likely to exit from work and had the highest number of absent workdays.

\section{METHODS}

\section{Data and study population}

The data used in the paper were drawn from the first two waves (2011 and 2013) of the China Health and Retirement Longitudinal Study (CHARLS) survey in China. The details of the survey can be found in Zhao et al. ${ }^{33}$ Generally speaking, CHARLS is designed in the similar way to the US Health and Retirement Study as a broad-purposed social science and health survey of people aged 45 or older and their spouses in China. It is a high-quality survey of nationally representative sample of Chinese residents. The national baseline survey for CHARLS was conducted between June 2011 and March 2012 and the respondents are followed every 2 years, using a face-to-face computer-assisted personal interview (CAPI). Samples were chosen through multistage probability sampling. In the first stage, 150 county-level units were randomly chosen with a probability proportional-to-size sampling technique from a sampling frame containing all county-level units with the exception of Tibet. The sample was stratified by region and within region by urban districts or rural counties and per capita statistics on gross domestic product. The final sample of 150 counties fell within 28 provinces. After excluding empty or non-resident dwellings, 12740 households were age-eligible for CHARLS. Final CAPI interviews were conducted on 10257 households, which included 17708 individual participants. The response rate of the survey was $80.5 \%$. Of the $19.5 \%$ rate of non-response, $8.8 \%$ was due to refusal to respond, $8.2 \%$ to unable to contact sample residents and $2.0 \%$ to other reasons. The survey contains detailed information on individual and household characteristics, such as individual demographics, work activities, health conditions, health services utilisation and insurance, physical measurements and household income, expenditure and assets.

Our study population was based on the CHARLS participants who engaged in either agricultural or non-agriculture work or both in 2011 and whose age was between 45 and 55 years for women or between 45 and 60 years for men in $2013(\mathrm{n}=4683)$. The age restriction was chosen according to the legal retirement age typically for those who are employed in the urban formal sectors in China. 
Although retirement age policy does not apply to the rural population, for comparison purpose, we chose the same age bands for participants who engaged in the agricultural job. We further restricted our study sample to those without missing data on labour participation status and other explanatory variables. As a result, our final sample used for analysing the effect of health status on work exit was 4332. Among them, 3942 individuals were still working in 2013 and eligible for the questions on number of absent workdays due to health problems. After removing sample with missing value on number of absent workdays, 3846 individuals were used for analysing the effect of health status on number of absent workdays.

\section{Measures}

Measurement of work exit and absenteeism

In the present paper, we measured two outcomes: work exit and the number of absent workdays due to health problems in 2013. Work exit status was determined by a series of questions in CHARLS (see section 1 of the online supplementary appendix). An individual was considered as 'working' if he or she engaged in agricultural work (including farming, forestry, fishing and husbandry for his or her own family or others) for more than 10 days in the past year or worked for at least 1 hour last week (such as earning a wage, running their own business and unpaid family business work) or was on leave but expected to go back or still received salary. Otherwise, an individual was considered as 'not working'. Since our study population was the CHARLS participants who were 'working' in 2011, 'not working' in 2013 was referred to as work exit.

The number of absent workdays due to health problems was measured based on the question, "How many days of work did you miss last year due to health problems?" for those who were still working in 2013, that is, those who engaged in household agricultural work, being employed or in non-farm self-employed and unpaid family business.

\section{Measurement of health and other controls}

SRH has been used extensively in epidemiological and economic studies not only as a measure of population health but also as a predictor of mortality, morbidity, healthcare utilisation and work exit. ${ }^{5891234-37}$ To be consistent with literature, we used SRH as our main health measure. The SRH (5-point Likert scale) in 2011 and 2013 were categorised into: good (reported good health or better than good health), fair (reported fair health) and poor (reported poor health or worth than poor health), respectively. The change of health status from 2011 to 2013 was defined by four categories: poor in 2011 to poor 2013, good/fair 2011 to poor 2013, poor 2011 to good/fair 2013, good/fair 2011 to good/fair 2013.

Other detailed health measures were used to construct an index of health to address the endogeneity and measurement error issues of the SRH, which was described in the Econometric models section. These measures included disability condition, number of chronic diseases and functional limitations. Other control variables included age, education (illiterate, lower than elementary school, elementary school graduate and middle school or higher), marriage status (married vs not) and monthly household expenditures on food, utilities, household items, clothing, medical care, taxes, etc. The detailed definition of the health-related and control variables are presented in section 2 of the online supplementary appendix.

\section{Patient and public involvement}

There was no public or patient involvement in the development of research question, the outcome measures, the design or implementation of the study.

\section{Econometric models}

There are a number of potential problems with the SRH. First, there might exist reverse causality between health and labour market status. ${ }^{38}{ }^{39}$ To address this, we measured the impact of health status before work exit on work exit (ie, the impact of health status in 2011 on work exit in 2013) to avoid the reverse causality. Second, the SRH may also suffer 'justification bias', that is, an individual could justify his or her work exit by reporting worse health status than his or her true health status. ${ }^{40}$ Third, due to individual heterogeneity, the SRH measure might not be comparable across respondents which means there may also be measurement error problem.

To address the potential endogeneity and measurement error of the SRH, we followed Bound et al $t^{\dagger}$ and used the latent variable model, which is analogous to using the three detailed health measures (ie, disability condition, number of chronic diseases and functional limitations) to construct an index of health. ${ }^{9} 1038$ Specifically, we used ordered Probit model for the SRH in $2011\left(H_{11}\right)$ and the change of SRH from 2011 to 2013. We carried out the full information maximum likelihood estimation method using SAS QLIM procedure. ${ }^{41}$ A number of goodness-of-fit measures (including different Pseudo R-squared) for the ordered Probit model for the SRH were conducted to show how well the three detailed measures predict SRH.

Two different model specifications were used: model I, to examine the effect of lagged health status by including $\mathrm{H}_{11}$ in the model; model II, to examine the effect of change in health status by including the change of SRH from 2011 to 2013 in the model. The specific model specifications were presented in section 3 of the online supplementary appendix. All analyses were weighted using the individual longitudinal weights provided by CHARLS. ${ }^{42}$

Similar method was used for absent workdays. We employed the Tobit model for the number of absent workdays and the ordered Probit models for the SRH in 2011 and the change of SRH. Tobit regression was used for the number of absent workdays due to health problems, as its value was truncated at zero with a large number of observations at the zero point.

Considering the gender difference in health and labour force participation, ${ }^{5912}$ the recommendation of gender-disaggregated analysis ${ }^{43-45}$ and the difference in population and polices between rural and urban areas 
mentioned above, we divided our sample into four separate groups according to gender and working types in 2011: female farmers (ie, any agricultural work), female non-farmers (non-agricultural work only), male farmers and male non-farmers. In addition, we also conducted a preliminary analysis by pooling all four groups and testing difference with interactions. The model parameters were reported in section 4 of the online supplementary appendix. It is shown that the impacts of health status on work exit marginally differ among the groups. Thus, based on both background knowledge and statistical testing, we conducted four separate group analyses.

\section{Interpreting estimated health coefficients}

It is difficult to interpret the magnitude of the estimated health coefficients in Probit model for work exit and Tobit model for the number of absent workdays. To help the interpretation, we presented the expected probability of work exit for each of the four categories of the change of health status from 2011 to $2013 .^{46}{ }^{47}$ To do this, we first assigned all individuals in our datasets to one of the four categories, and then calculated the expected probability of work exit for each individual using their own levels for the control variables (ie, age, education, marriage status and expenditures in 2011) and the assigned category of the change of health status. Last, we reported the mean value of the expected probability of work exit among all individuals. For absent workdays, we calculated the average expected number of absent workday following the same method.

\section{Sensitivity analysis}

We conducted all the analyses without using the weights and conducted the analyses by including all older farmers without applying the age restriction.

\section{RESULTS}

Table 1 presents our sample characteristics in 2011 by gender and by our four separate working groups: female farmers, female non-farmers, male farmers and male non-farmers. About 36\% of women and $39 \%$ of men were non-farmers (weighted proportion), that is, engaged in non-agricultural work only in 2011. Not surprisingly, non-farmers' education level was much higher than that of farmers and men's education was higher than that of women. In terms of SRH, farmers and women had poorer SRH than non-farmers and men, respectively. Consistently, farmers were more likely to be disabled, and suffered from more chronic diseases and functional limitations than non-farmers, regardless of gender.

Table 2 presents the percentage of work exit and the number of absent workdays in 2013 by gender and work type. Overall, about 90\% were still working in 2013. Regarding each gender and work type group, $18.5 \%$ of female non-farmers and $12.0 \%$ of male non-farmers stopped work in 2013, while the percentages for female and male farmers were $11.0 \%$ and $4.9 \%$, respectively.
Conditional on keeping working in 2013, for farmers, the number of absent workdays was 16.6 days for women and 15.0 days for men. For non-farmers, the numbers were 5.6 and 4.9 days for women and men, respectively. Table 2 also shows possible associations among work exit/absenteeism, the SRH in 2011, 2013 and the change of SRH from 2011 to 2013. People in poor health status in 2011 or 2013 had the highest percentage of work exit within each gender and work type group except for female non-farmers. The recent health deterioration (good/fair to poor) and persistently poor health (poor to poor) were associated with a higher probability of work exit for both females and males but this relationship was not shown among non-farmers after further breaking the population down by farmers and non-farmers. In terms of absent workdays, people in poor health status in 2011 and 2013, respectively, or in persistently poor health status over time had the largest number of absent workdays across all the groups.

\section{Validation of constructed health measure}

Table 3 presents a number of goodness-of-fit measures (including different Pseudo R-squared) for the ordered Probit model for the SRH to show how well the three detailed measures predict SRH. Different Pseudo $\mathrm{R}^{2} \mathrm{~s}$ were used to indicate how well these health measures explain SRH. According to Louviere et al, (p54) ${ }^{48}$ one should not expect to obtain pseudo $\mathrm{R}^{2}$ values as high as the $\mathrm{R}^{2}$ commonly obtained in ordinary least squared (OLS) regression applications. For instance, values of McFadden's likelihood ratio index (LRI) between 0.2 and 0.4 indicate extremely good model fits which is approximately equivalence to $0.7-0.9$ for $\mathrm{R}^{2}$ from OLS based on simulations. Therefore, our pseudo $R^{2}$ values (McFadden's LRI ranged from 0.09 to 0.18 ) suggested that the detailed health measures moderately to strongly explained SRHs.

\section{Work exit}

Table 4 presents the analytical results of model I for the impact of 2-year lagged health only and model II for the impact of the change of health status over time. Other parameter estimates are presented in section 5 of the online supplementary appendix. Results of model I showed that farmers in poor health status in 2011 were more likely to stop work than those in good health in 2011 (model parameter $0.655(\mathrm{p} \leq 0.05)$ for women and model parameter $0.810(\mathrm{p} \leq 0.01)$ for men). Results of model II showed that people who changed health status from poor to poor, good/fair to poor and poor to good/ fair were significantly more likely to exit from work than people with persistently good status except for female non-farmers. For example, among female farmers, the probabilities of work exit were significantly higher for those who changed health status from poor to poor (model parameter $0.752(\mathrm{p} \leq 0.01))$, good/fair to poor (model parameter $0.763(\mathrm{p} \leq 0.01))$ and poor to good/ fair (model parameter $0.415(\mathrm{p} \leq 0.05))$ than those with 


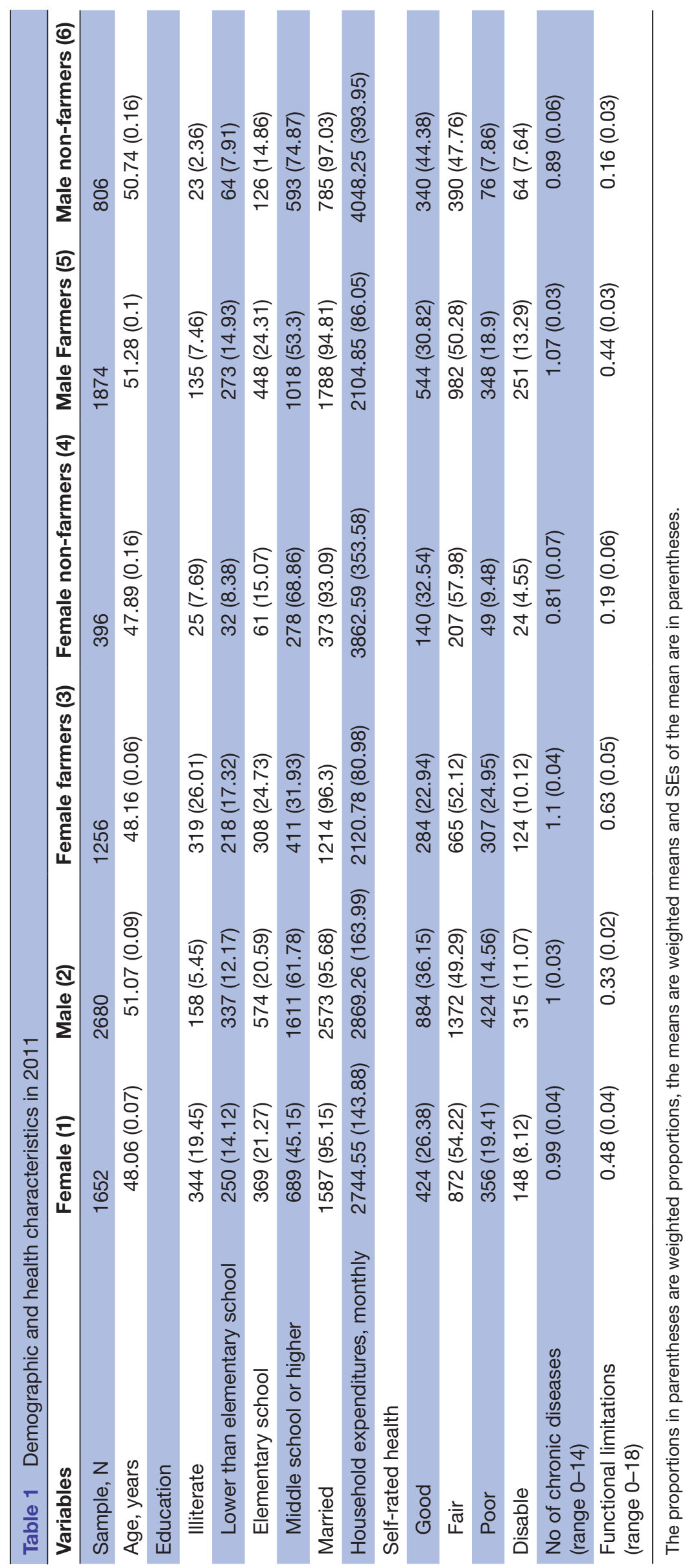




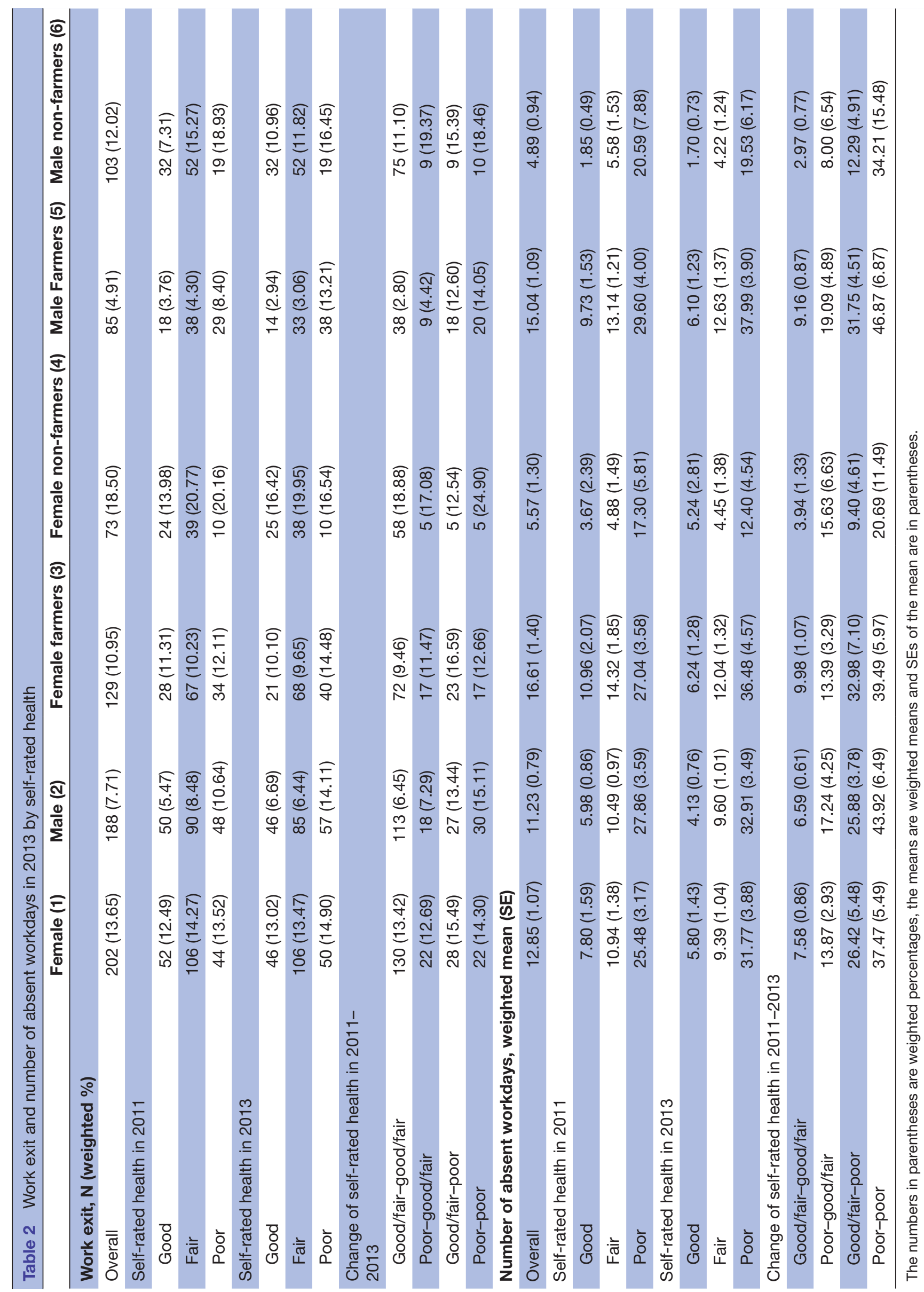




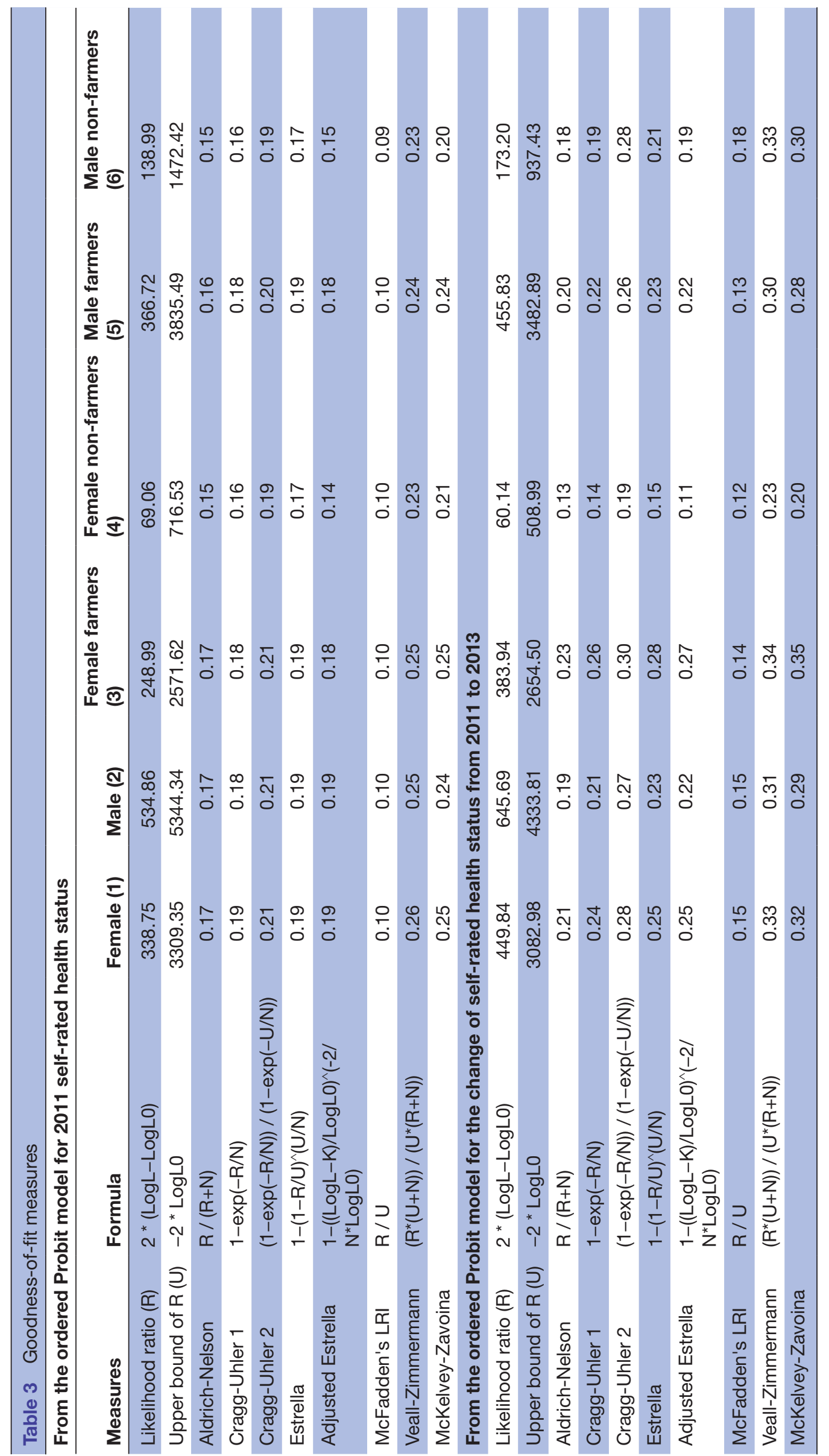




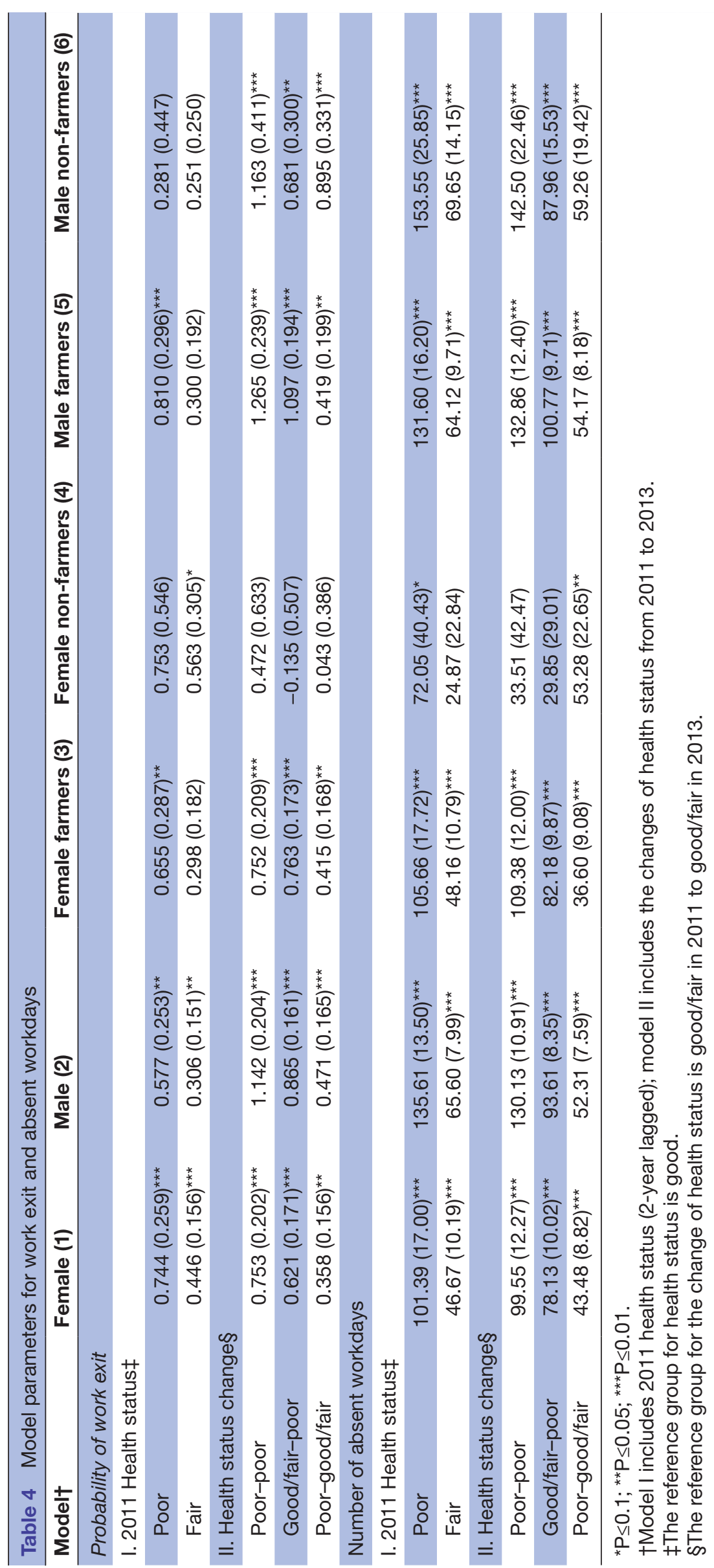


Table 5 Expected probability of work exit and expected number of absent workdays by 2011 health status

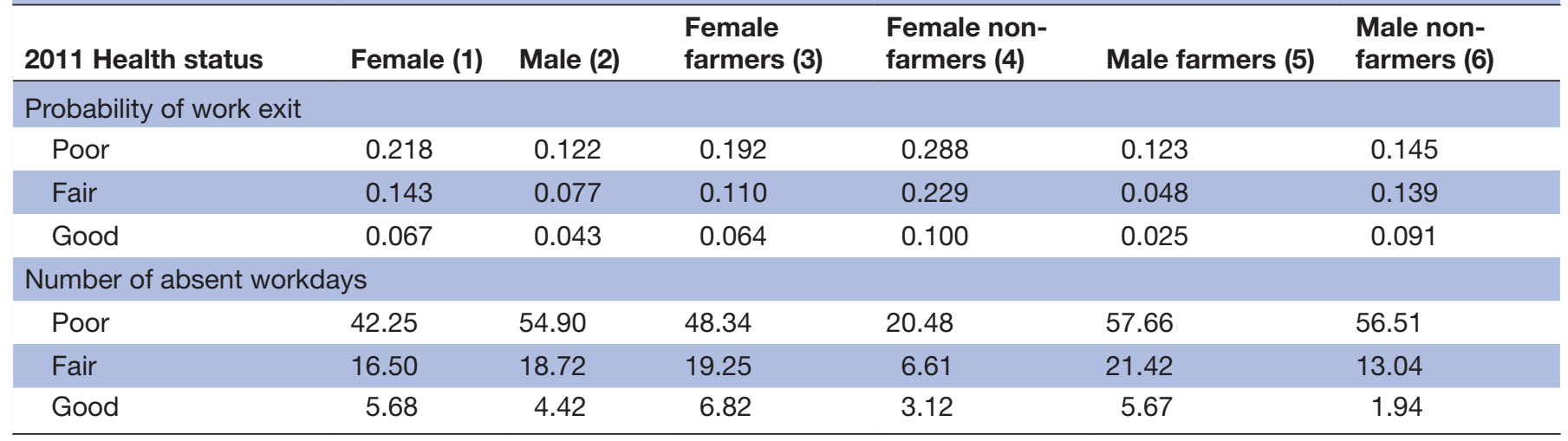

persistently good health status (the reference group). The expected values shown in tables 5 and 6 are more helpful in understanding the magnitudes of the effects. Across all groups except for female farmers and female non-farmers, people with persistently poor health had the highest probability of work exit, for example, 0.28 for all males with persistently poor health compared with 0.05 for those with persistently good health. There was then a decreasing trend of probability of work exit among farmers with health status change from good/fair to poor, poor to good/fair and then good to good. However, this trend did not hold for non-farmers.

\section{Number of absent workdays due to health problems}

Among those who were still working in 2013, the overall average number of absent workdays due to health problems was 12 days $(\mathrm{SE}=0.63)$. The average number of absent workdays among farmers (16.6 (1.4) for women and 15.0 (1.1) for men), much higher than non-farmers (5.6 (1.3) and $4.9(0.9)$, respectively) (table 2). All older working people with poorer health status had significantly more number of absent workdays due to health problems (tables 4 and 5). When analysing the impact of the change of health status over time, the model parameters (table 4) and expected values (table 6) showed a decreasing trend with persistently poor status leading to the largest number of absent workdays, followed by the changes from good/fair to poor, from poor to good/fair and persistently good/fair. The exception was found in female non-farmers.

\section{Sensitivity analyses}

The analysis results without using the weights provided by CHARLS were consistent with the main analysis results considering the weights. In addition, after dropping the age restriction for farmers, we observed similar effects (in terms of magnitude and significance) of the lagged health status and the change of health status over time. The detailed results can be found in section 6 of the online supplementary appendix.

\section{DISCUSSION}

The effect of health status on work exit and absent workdays among older working people in China has not been extensively studied. This present paper fills the gap by examining the impact of the 2-year lagged health status and the change of health status over time on work exit and absent workdays in a representative older working population sample in China. We found that the effects of health status varied by the two outcomes (ie, work exit and absent workdays) as well as by both gender and

Table 6 Expected probability of work exit and expected number of absent workdays by the change of health status over time

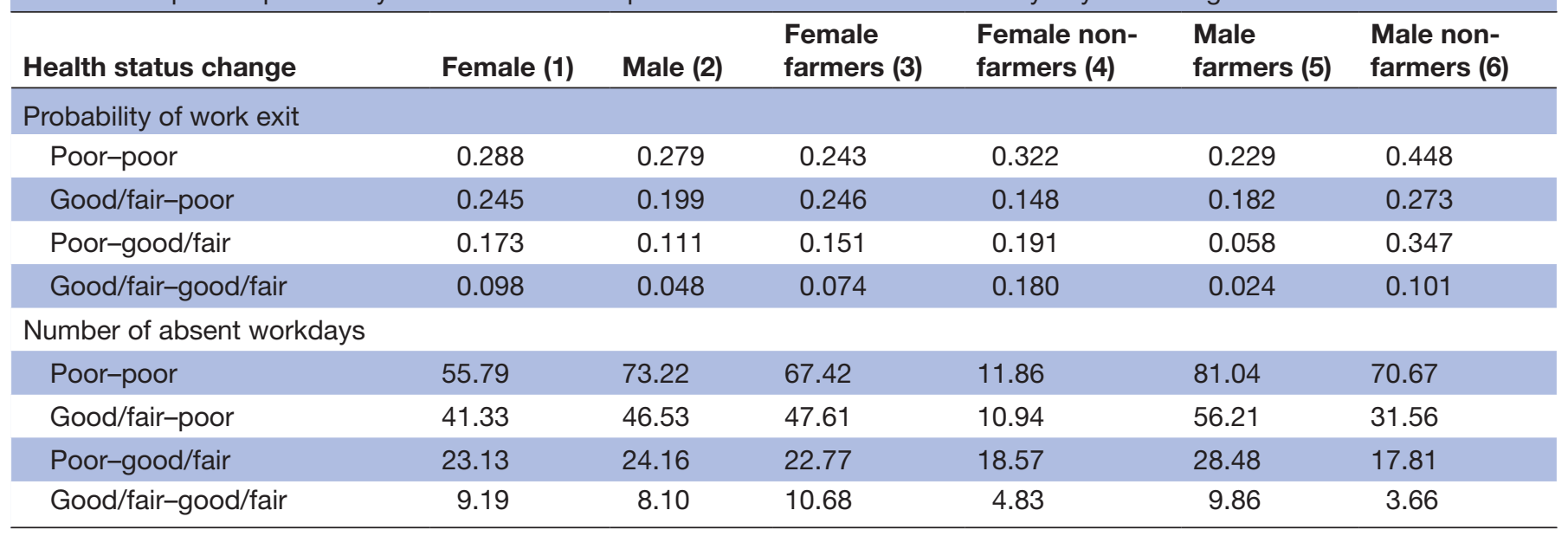


working types (agricultural work vs non-agricultural work). Two-year lagged health status had significant effects on work exit among female and male farmers but not among non-farmers. In addition, the older workers (except female non-farmers) with poor health in either 2011 or both 2011 and 2013 were significantly more likely to exit from work or missed more workdays than those with persistently good health over time. Those with persistently poor health or recent health deterioration incurred the highest probability of work exit and number of absent workdays except for female non-farmers.

Many studies have investigated the relationship between health and labour force participation or work exit among older workers in the developed countries. ${ }^{5-13}$ For example, Bound et al investigated the dynamic effects of health on labour force behaviour of older workers using US data and found that poor health led many older workers to withdraw from the labour force. ${ }^{9}$ In addition, respondents whose health declined relatively recently were more likely to exit from the labour force than those whose health declined earlier. ${ }^{9}$ Disney et al demonstrated that ill health predicted individual retirement behaviour among workers aged from 50 until state pension age in Britain. ${ }^{10}$ van den Berg et al showed that poor SRH was strongly associated with exit from paid employment due to retirement, unemployment or disability among older workers in 11 European countries. ${ }^{7}$ However, there are very few such studies in the developing countries. Consistent with findings in literature, our study showed that female or male older workers with poor health (without further distinguishing farmers and non-farmers) were significantly more likely to exit from work. In contrast to Bound $e t a l,{ }^{9}$ we found that female or male older workers with persistently poor health incurred the highest probability of work exit. The discrepancy might be due to different populations, labour force markets and social security systems.

Our study revealed the important differences between farmers and non-farmers as well as between males and females in tables 1 and 2. Farmers generally had worse health status than non-farmers. However, the work exit rate was lower in farmers than in non-farmers which is consistent with previous studies. ${ }^{3} 494$ However, conditional on keeping working in 2013, the number of absent workdays for farmers was found to be higher than that of non-farmers. One possible explanation is that since social security schemes have not been fully implemented in rural areas and agricultural income is the main source of income for older farmers, they have to continue their work to late life. The other possible explanation is that poorer health status of farmers compared with non-farmers causes them to take more sick leaves while remaining working. In addition, we found that health status was not a significant factor leading to work exit for female non-farmers which suggests that work exit of female non-farmers is attributable to factors other than health. The improvement in health status only might not keep female non-farmers at work.
In our population selection, we restricted to women between 45 and 55 years and men between 45 and 60 years in 2013 based on the retirement age policy that is applied to the urban formal sectors in China. However, this policy does not apply to the rural population (ie, those in agricultural work). We therefore conducted sensitivity analyses by including all older working farmers without the age restriction. It showed that the effects of health status were similar to our main analysis results by applying the age restriction and relaxing the age restriction did not affect our conclusion on the influence of health status on work exit and the number of absent workdays for farmers.

One of our limitations is that when analysing the impact on work exit, we did not further distinguish those who were not working in 2013 by their work exit routes, for example, retirement, disability (due to health reasons) or other reasons due to the small sample size for the subgroups. We found neither health reasons nor retirement was the major reason for the work exit in 2013. Specifically, about $25 \%$ of female farmers and $40 \%$ of male farmers were not working due to health reasons and these proportions went up to $33 \%$ and $41 \%$, respectively, if we dropped the age restriction. Only $2 \%$ of female and male farmers were not working due to retirement and the proportions did not change much if we dropped the age restriction $(2 \%$ of female farmers and $5 \%$ of male farmers). The detailed reasons of work exit for different groups can be found in section 7 of the online supplementary appendix. The small proportion of retirement for farmers was partially due to the lack of retirement and pension schemes for rural population in China. ${ }^{49}$ On the other hand, about $5 \%$ and $27 \%$ of female non-farmers and $20 \%$ and $8 \%$ of male non-farmers stopped working due to health reasons and retirement, respectively. Therefore, the effects of health status on work exit were comparable in the three groups (female farmers, male farmers and male non-farmers) because of their similar work exit routes. Also, the facts that very few female non-farmers stopped working due to health reasons and relatively high proportion of female non-farmers stopped working due to retirement partially confirm our explanation that work exit of female non-farmers is attributable to factors other than health.

In the present study, we only selected working population in 2011. People in poor health in 2011 who continued working in 2013 might have unobserved characteristics that encouraged them to work. For example, they might be in better health status than our health measures suggested or had a strong commitment to their work. ${ }^{9}$ Therefore, we may have underestimated the effect of health status. However, we were more interested in examining the effect of health on the decision whether to continue working among the older people who had been already in the labour force. Therefore, our study findings are more relevant to the policies that attempt to retain the existing older working population through improving their health.

The proportion of older workers is expected to increase among the working population in China, which will 
be further exacerbated by China's recent plan to raise the official retirement age. ${ }^{50}$ Our study has important policy implications for China and other low-income and middle-income countries. Female non-farmers currently have earlier legal retirement age than male non-farmers and our findings indicate that female non-farmers might have to stop working due to the legal retirement age requirement instead of health. Therefore, more research is needed to investigate whether the legal retirement age should be extended for female non-farmers. Since exit from labour force is generally not reversible at an older age particularly for non-farmers, the priority should be given to the policies that better improve the overall workers' health status and improve the work circumstances of workers especially with persistently poor health. In addition, having realised the problem of lacking old-age security for the rural elderly, China government launched a nationwide, experimental rural social pension plan in 2009 , which is expected to cover $10 \%$ of rural regions by the end of 2009 , about $50 \%$ by 2012 , and $100 \%$ by $2020 .^{51}$ However, our and previous findings using the same data indicated that the new pension plan did not affect the labour supply of rural elderly, as the majority of the elderly population sampled continued to work into their seventies. Our findings of older farmers taking more sick leaves while remaining in the labour force also suggest an unproductive rural labour force. It may indicate that the new pension plan has not provided enough social security for the elderly in rural China or there is a lack of knowledge and awareness of such pension plan. More research is needed in the future to explore the reasons why rural elderly still keep working under the new pension plan and accurately estimate the effect of the new pension plan on welfare of rural elderly.

In conclusion, poor 2-year lagged health predicts work exit for both male and female farmers, and increases the absent work days in all older working population. Persistently poor health or recent health deterioration over time has detrimental impact on labour market in terms of work exit and absenteeism among all older Chinese workers except for female non-farmers.

Contributors XL and WZ designed the study, developed data analysis plan and equally contributed to this study. HS performed statistical analysis of the data. AHA provided guidance on economic theory and analysis. All authors made significant contributions to the interpretation of results and participated in drafting and revising the manuscript. All authors have approved the final version.

Funding The authors have not declared a specific grant for this research from any funding agency in the public, commercial or not-for-profit sectors.

Competing interests None declared.

Patient consent for publication Not required.

Ethics approval The original CHARLS was approved by the ethics review committee of Peking University.

Provenance and peer review Not commissioned; externally peer reviewed.

Data availability statement Data are available in a public, open access repository.

Open access This is an open access article distributed in accordance with the Creative Commons Attribution Non Commercial (CC BY-NC 4.0) license, which permits others to distribute, remix, adapt, build upon this work non-commercially, and license their derivative works on different terms, provided the original work is properly cited, appropriate credit is given, any changes made indicated, and the use is non-commercial. See: http://creativecommons.org/licenses/by-nc/4.0/.

\section{REFERENCES}

1. China Power Team. Does China have an aging problem? China power, 2016Published February 15. Available: https://chinapower. csis.org/aging-problem/ [Accessed 24 Apr 2018].

2. Zeng $Y$, Hesketh T. The effects of China's universal two-child policy. The Lancet 2016;388:1930-8.

3. CHARLS Research Team. Challenges of population aging in China: evidence from the National baseline survey of the China health and retirement longitudinal study (CHARLS, 2013National School of Development, Peking UniversityMay.

4. Giles J, Wang D, Cai W. The Labor Supply and Retirement Behavior of China's Older Workers and Elderly in Comparative Perspective. National Academies Press (US), 2012. https://www.ncbi.nlm.nih.gov/ books/NBK109217/. (Accessed 24 Oct 2017).

5. Cai L, Kalb G. Health status and labour force participation: evidence from Australia. Health Econ 2006;15:241-61.

6. van Rijn RM, Robroek SJW, Brouwer S, et al. Influence of poor health on exit from paid employment: a systematic review. Occup Environ Med 2014;71:295-301.

7. van den Berg T, Schuring M, Avendano M, et al. The impact of ill health on exit from paid employment in Europe among older workers. Occup Environ Med 2010;67:845-52.

8. Mortelmans D, Vannieuwenhuyze JTA. The age-dependent influence of self-reported health and job characteristics on retirement. Int J Public Health 2013;58:13-22.

9. Bound J, Schoenbaum M, Stinebrickner TR, et al. The dynamic effects of health on the labor force transitions of older workers. Labour Econ 1999;6:179-202.

10. Disney R, Emmerson C, Wakefield M. III health and retirement in Britain: a panel data-based analysis. J Health Econ 2006;25:621-49.

11. Bambra C, Eikemo TA, regimes Wstate. Welfare state regimes, unemployment and health: a comparative study of the relationship between unemployment and self-reported health in 23 European countries. Journal of Epidemiology \& Community Health 2009;63:92-8.

12. Au DWH, Crossley TF, Schellhorn M. The effect of health changes and long-term health on the work activity of older Canadians. Health Econ 2005;14:999-1018.

13. Cai L, Kalb G. Health status and labour force status of older working-age Australian men. Australian Journal of Labour Economics 2007;10:227-52.

14. Karpansalo Met al. Depression and early retirement: prospective population based study in middle aged men. Journal of Epidemiology \& Community Health 2005;59:70-4.

15. Geuskens GA, Burdorf A, Hazes JMW. Consequences of rheumatoid arthritis for performance of social roles--a literature review. J Rheumatol 2007;34:1248-60.

16. Vijan S, Hayward RA, Langa KM. The impact of diabetes on workforce participation: results from a national household sample. Health Serv Res 2004;39:1653-70.

17. de Boer AGEM, Taskila T, Ojajärvi A, et al. Cancer survivors and unemployment: a meta-analysis and meta-regression. JAMA 2009;301:753-62.

18. Leijten FRM, de Wind A, van den Heuvel SG, et al. The influence of chronic health problems and work-related factors on loss of paid employment among older workers. J Epidemiol Community Health 2015;69:1058-65.

19. Zhang W, Bansback N, Kopec J, et al. Measuring time input loss among patients with rheumatoid arthritis: validity and reliability of the valuation of lost productivity questionnaire. J Occup Environ Med 2011b;53:530-6.

20. Tangka FK, Trogdon JG, Nwaise I, et al. State-Level estimates of cancer-related absenteeism costs. Journal of Occupational and Environmental Medicine 2013;55:1015-20.

21. Dewa CS, Loong D, Bonato S, et al. Incidence rates of sickness absence related to mental disorders: a systematic literature review. BMC Public Health 2014;14:205.

22. Patel JG, Nagar SP, Dalal AA. Indirect costs in chronic obstructive pulmonary disease: a review of the economic burden on employers and individuals in the United States. Int J Chron Obstruct Pulmon Dis 2014;9:289-300.

23. Sadatsafavi M, Rousseau R, Chen W, et al. The preventable burden of productivity loss due to suboptimal asthma control: a populationbased study. Chest 2014;145:787-93. 
24. Wynne-Jones G, Cowen J, Jordan JL, et al. Absence from work and return to work in people with back pain: a systematic review and meta-analysis. Occup Environ Med 2014;71:448-56.

25. Ghushchyan V, Nair KV, Page RL. Indirect and direct costs of acute coronary syndromes with comorbid atrial fibrillation, heart failure, or both. Vasc Health Risk Managment 2015;11:25-34.

26. Zhang W, McLeod C, Koehoorn M. The relationship between chronic conditions and absenteeism and associated costs in Canada. Scand $J$ Work Environ Health 2016;42:413-22.

27. de Vroome EMM, Uegaki K, van der Ploeg CPB, et al. Burden of sickness absence due to chronic disease in the Dutch workforce from 2007 to 2011. J Occup Rehabil 2015;25:675-84.

28. Kessler RC, Greenberg PE, Mickelson KD, et al. The effects of chronic medical conditions on work loss and work cutback. J Occup Environ Med 2001;43:218-25.

29. Loeppke R, Taitel M, Haufle V, et al. Health and productivity as a business strategy: a Multiemployer study. J Occup Environ Med 2009;51:411-28.

30. Mitchell RJ, Bates P. Measuring health-related productivity loss. Popul Health Manag 2011;14:93-8.

31. Zhang W, Sun H, Li X. The association between chronic conditions and non-agricultural work productivity loss among the middle-aged Chinese population. J Occup Environ Med 2018;60:832-8.

32. Pohl V, Neilson C, Parro F. Health shocks, education, and labor market outcomes. Working paper, 2014.

33. Zhao Y, Hu Y, Smith JP, et al. Cohort profile: the China health and retirement longitudinal study (CHARLS). Int $J$ Epidemiol 2014;43:61-8.

34. Idler EL, Benyamini Y. Self-Rated health and mortality: a review of twenty-seven community studies. J Health Soc Behav 1997;38:21-37.

35. Mavaddat N, Parker RA, Sanderson S, et al. Relationship of selfrated health with fatal and non-fatal outcomes in cardiovascular disease: a systematic review and meta-analysis. PLoS One 2014;9:e103509.

36. Hornby-Turner YC, Peel NM, Hubbard RE. Health assets in older age: a systematic review. BMJ Open 2017;7:e013226.

37. Bilgel F, Karahasan BC. Self-Rated health and endogenous selection into primary care. Soc Sci Med 2018;197:168-82.
38. Dwyer DS, Mitchell OS. Health problems as determinants of retirement: are self-rated measures endogenous? J Health Econ 1999;18:173-93.

39. García Gómez P, López Nicolás A. Health shocks, employment and income in the Spanish labour market. Health Econ 2006;15:997-1009.

40. Bound J. Self-Reported versus objective measures of health in retirement models. J Hum Resour 1991;26:106-38.

41. SAS Institute Inc,. The QLIM Procedure, in: SASIETS $₫ 13.2$ User's Guide. SAS Institute Inc. NC, USA: Cary, 2014.

42. CHARLS. China health and retirement longitudinal study followup 2013 release notePublished November 2015. Available: http:// charls.pku.edu.cn/uploads/document/2013-charls-wave2/ application/CHARLS_Wave2_Release_Note.pdf [Accessed 30 Jun 2019].

43. Nowatzki N, Grant KR. Sex is not enough: the need for genderbased analysis in health research. Health Care Women Int 2011;32:263-77.

44. Day S, Mason R, Lagosky S, et al. Integrating and evaluating sex and gender in health research. Health Res Policy Syst 2016;14.

45. Canadian Institutes of Health Research. Key considerations for the appropriate integration of sex and gender in research, 2018Published February 12. Available: http://www.cihr-irsc.gc.ca/e/50835.html. [Accessed 20 Feb 2019].

46. Wooldridge JM. Econometric analysis of cross section of panel data, Cambridge. MA: MIT Press, 2002

47. Greene WH. Econometric analysis, 7 edition. Prentice Hall. Boston 2011.

48. Louviere JJ, Hensher DA, Swait JD. "Stated Choice Methods: Analysis and Applications". Cambridge University Press, 2000.

49. Lai MH. Elder's employment and cohort change. Social Science of Beijing 2017;3:102-10. (in Chinese).

50. Reuters. China will set plan for raising retirement age next year: media. Reuters, 2016Published February 28. Available: https:// www.reuters.com/article/us-china-labour-retirement/china-will-setplan-for-raising-retirement-age-next-year-media-idUSKCNOW1077 [Accessed 16 Apr 2018.].

51. Shen C, Williamson JB. China's new rural pension scheme: can it be improved? Int J Sociol Soc Policy 2010;30:239-50. 